\title{
Transcriptional analysis of the Escherichia coli ColV-la plasmid pS88 during growth in human serum and urine
}

\author{
Chloé Lemaître ${ }^{1,2}$, Philippe Bidet ${ }^{1,2}$, Edouard Bingen ${ }^{1,2}$ and Stéphane Bonacorsi ${ }^{1,2^{*}}$
}

\begin{abstract}
Background: The sequenced O45:K1:H7 Escherichia coli meningitis strain 588 harbors a large virulence plasmid. To identify possible genetic determinants of pS88 virulence, we examined the transcriptomes of 88 plasmidic ORFs corresponding to known and putative virulence genes, and 35 ORFs of unknown function.

Results: Quantification of plasmidic transcripts was obtained by quantitative real-time reverse transcription of extracted RNA, normalized on three housekeeping genes. The transcriptome of E. coli strain 588 grown in human serum and urine ex vivo were compared to that obtained during growth in Luria Bertani broth, with and without iron depletion. We also analyzed the transcriptome of a pS88-like plasmid recovered from a neonate with urinary tract infection. The transcriptome obtained after ex vivo growth in serum and urine was very similar to those obtained in iron-depleted LB broth. Genes encoding iron acquisition systems were strongly upregulated. ShiF and ORF 123, two ORFs encoding protein with hypothetical function and physically linked to aerobactin and salmochelin loci, respectively, were also highly expressed in iron-depleted conditions and may correspond to ancillary iron acquisition genes. Four ORFs were induced ex vivo, independently of the iron concentration. Other putative virulence genes such as iss, etsC, ompTp and hlyF were not upregulated in any of the conditions studied. Transcriptome analysis of the pS88-like plasmid recovered in vivo showed a similar pattern of induction but at much higher levels.
\end{abstract}

Conclusion: We identify new pS88 genes potentially involved in the growth of E. coli meningitis strain S88 in human serum and urine.

Keywords: Escherichia coli, Plasmid, Transcriptome, RNA, Virulence, Iron, Siderophore

\section{Background}

Escherichia coli clone O45:K1:H7, belonging to virulence sequence type (ST)95, is a major cause of neonatal meningitis and of urosepsis in young infants in France [1,2]. The recently sequenced O45:K1:H7 strain S88, isolated from cerebrospinal fluid of a neonate, harbors a plasmid of $134 \mathrm{~kb}$, named pS88, involved in meningeal virulence and bacteremia [3]. Epidemiological studies have shown that major genetic determinants of this plasmid are not restricted to E. coli clone O45:K1:H7 but are widely distributed among E. coli neonatal meningitis (ECNM)

\footnotetext{
*Correspondence: stephane.bonacorsi@rdb.aphp.fr

'Univ Paris Diderot, Sorbonne Paris Cité, EA 3105, Paris F-75205, France ${ }^{2}$ AP-HP, Laboratoire de Microbiologie, Hôpital Robert-Debré, Paris F-75019, France
}

\section{Biomed Central}

clones, uropathogenic E. coli strains (UPEC), and avian pathogenic E. coli strains (APEC) [3-6]. Sequencing of pS88 revealed 157 ORFs, including genes involved in the plasmid machinery (transfer, maintenance and replication), IS-like genes, two colicins (colicin Ia and microcin $\mathrm{V}$ ), and several virulence genes of known or putative functions, such iron-uptake system. These iron-uptake systems include aerobactin (iucABCD and iutA), salmochelin (iroBCDEN) and the SitABCD transport system [7-9]. The S88 plasmid also contains the serum survival gene iss $[10,11]$, the ets $A B C$ genes, encoding a putative type 1 secretion system [4], omp $T_{p}$, encoding a putative outer-membrane protease differing from the E. coli chromosomal ompT gene [12] and hlyF, encoding a hemolysin [13]. Finally, 35 ORFs have unknown functions and may represent new virulence genes. 
Few studies have analyzed the transcriptional profile of human extraintestinal E. coli (ExPEC) strains responsible for urinary tract infection [14-17]. To further unravel the role of pS88 in the virulence of clone O45:K1:H7, we analyzed the transcriptional response of plasmid pS88 to growth in urine and serum, representing two steps required for meningeal invasion [18-21]. We also analyzed the transcriptome of a pS88-like plasmid recovered from a neonate with urinary tract infection (UTI).

\section{Results and discussion}

\section{Validation of transcriptional analysis}

The transcriptional analysis was validated first by qRTPCR amplification of transcripts of 5 genes (2 housekeeping genes and 3 plasmidic genes) in serial dilutions of RNA extracted from S88 grown in LB broth. The Ct values showed a linear relation with the template dilution (Figure 1A). Similar results were obtained after growth in LB broth containing the iron chelator 2,2'dipyridyl (data not shown). We also conduced three independent biological replicates of pS88 after growth in LB Broth, named experiments 1, 2 and 3, to compare the $\mathrm{Ct}$ values which each other. As expected, most of the fold changes were close to 1 , and $98 \%$ of values were between 0.25 and 4 (Figure 1B). Therefore, we considered that an ORF was upregulated or downregulated if the change in expression was smaller or larger than 0.25 -fold and 4-fold, respectively, with $p$ values $\leq 0.05$. These thresholds are in line with those selected by Mobley et al. [16].

\section{Global analysis of the pS88 transcriptome ex vivo and the pAMM transcriptome in vivo}

Table 1 shows the transcriptome patterns for pS88 grown in iron-depleted LB, in human urine and serum, as well as that of PAMM (recovered from human urine in vivo). A transcript was detected for all 88 ORFs tested, except for ORF 23. Overall, 18 ORFs (19\%), 10 of which corresponded to 5 operons, were upregulated in at least one of the three ex vivo conditions. The only down-regulated genes were $\operatorname{tra} A$ in urine, and $y d f A$ and ORF 132 in iron-depleted LB broth. The transcriptome pattern of pAMM largely matched the ex vivo patterns, indicating that growth in human urine ex vivo was a relevant model. Interestingly, the fold changes observed in vivo were far higher than those observed ex vivo and in vitro.

A

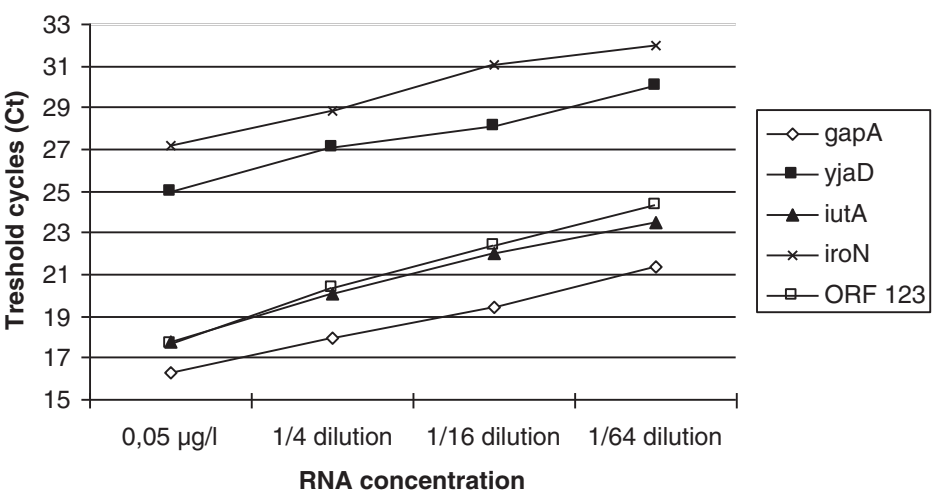

B

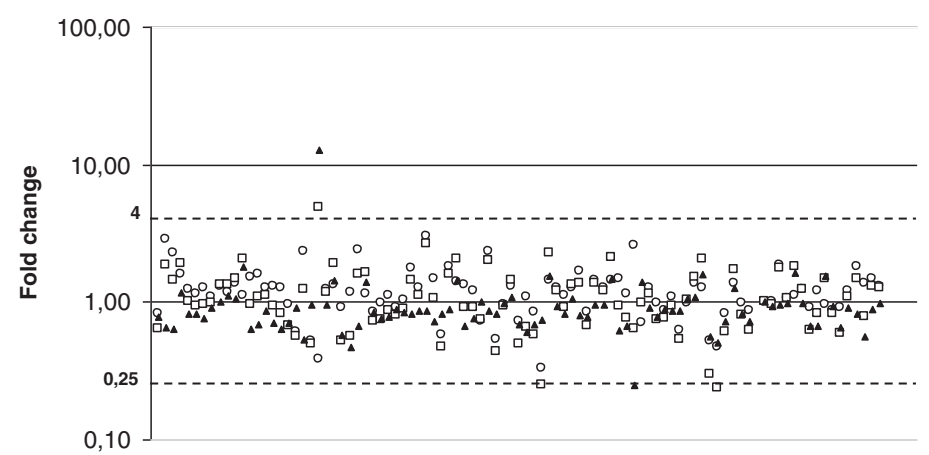

Figure 1 Linearity and reproducibility of transcriptional analysis. (A) Quantitative RT-PCR of 5 ORFs using different RNA concentrations. (B) Analysis of fold changes in RNA transcript abundance by the $2^{-\Delta \Delta C T}$ method across 3 biological replicates named experiments 1,2 and 3 after growth in LB broth (experiment 1 vs 2: dots, experiment 1 vs 3: squares, experiment 2 vs 3: triangles). The fold changes fall within the range $0.25-4.00$ in $98 \%$ of cases. 
Table 1 Transcriptional expression of pS88 and PAMM ORFs in different growth conditions compared to LB broth

\begin{tabular}{|c|c|c|c|c|c|c|c|c|c|}
\hline Name & Gene & Function & $\begin{array}{l}\text { LB with iron } \\
\text { chelator }^{\mathrm{a}} \text { pS88 }\end{array}$ & $p^{\mathbf{b}}$ & $\begin{array}{l}\text { Human serum } \\
\text { ex vivo }{ }^{\mathrm{a}} \mathrm{pS} 88\end{array}$ & $p^{\mathbf{b}}$ & $\begin{array}{l}\text { Human urine } \\
\text { ex vivo }^{\mathrm{a}} \text { pS88 }\end{array}$ & $p^{\mathbf{b}}$ & $\begin{array}{c}\text { Human urine } \\
\text { in vivo }{ }^{\mathrm{a}} \mathrm{pAMM} \\
\end{array}$ \\
\hline pS88001 & int & Putative site-specific recombinase & 0.85 & 0.775 & 0.59 & 0.427 & 0.73 & 0.505 & 0.84 \\
\hline pS88002 & repA & RepFIB replication protein RepA & 0.41 & 0.305 & 0.97 & 0.976 & 0.89 & 0.889 & 3.56 \\
\hline pS88003 & & Conserved hypothetical protein & 1.67 & 0.496 & 1.26 & 0.758 & 3.09 & 0.159 & 7.26 \\
\hline pS88004 & & Conserved hypothetical protein & 0.93 & 0.883 & 0.58 & 0.266 & 0.60 & 0.459 & 2.52 \\
\hline pS88006 & & $\begin{array}{l}\text { Putative fragment of ImpB UV } \\
\text { protection protein }\end{array}$ & 0.48 & 0.578 & 0.77 & 0.550 & 1.51 & 0.367 & 1.17 \\
\hline pS88009 & iutA & Ferric aerobactin receptor precursor lutA & 4.12 & 0.007 & 4.23 & 0.006 & 4.01 & 0.048 & 9.02 \\
\hline pS88013 & incA & $\begin{array}{l}\text { Aerobactin siderophore biosynthesis } \\
\text { protein lucA }\end{array}$ & 45.25 & 0.005 & 15.85 & 0.023 & 18.38 & 0.026 & 168.12 \\
\hline pS88014 & shiF & Putative membrane transport protein ShiF & 7.66 & 0.006 & 14.03 & 0.005 & 14.19 & 0.004 & 17.71 \\
\hline pS88015 & & $\begin{array}{l}\text { Putative membrane protein; CrcB-like } \\
\text { protein }\end{array}$ & 2.40 & 0.105 & 0.82 & 0.807 & 4.19 & 0.051 & 6.08 \\
\hline pS88016 & & Conserved hypothetical protein & 1.77 & 0.250 & 1.65 & 0.628 & 4.14 & 0.066 & 9.74 \\
\hline pS88017 & & Putative enolase & 1.47 & 0.573 & 5.44 & 0.152 & 7.98 & 0.040 & 18.68 \\
\hline pS88019 & sitD & SitD protein; iron transport protein & 4.54 & 0.020 & 38.23 & 0.003 & 26.29 & 0.004 & 139.75 \\
\hline pS88022 & sitA & SitA protein; iron transport protein & 17.79 & 0.002 & 49.52 & 0.003 & 83.87 & 0.001 & 776.05 \\
\hline pS88026 & & Hypothetical protein & 1.32 & 0.633 & 1.04 & 0.959 & 1.02 & 0.981 & r \\
\hline pS88027 & & $\begin{array}{l}\text { Hypothetical protein; putative } \\
\text { exported protein }\end{array}$ & 0.70 & 0.626 & 1.04 & 0.956 & 0.31 & 0.187 & / \\
\hline pS88028 & & Conserved hypothetical protein & 1.11 & 0.809 & 0.75 & 0.577 & 1.16 & 0.762 & / \\
\hline pS88029 & & Conserved hypothetical protein & 1.30 & 0.712 & 1.22 & 0.751 & 2.20 & 0.260 & / \\
\hline pS88030 & & Conserved hypothetical protein & 0.30 & 0.098 & 0.46 & 0.308 & 0.32 & 0.143 & 1.09 \\
\hline pS88031 & & Hypothetical protein & 0.67 & 0.405 & 0.97 & 0.959 & 1.58 & 0.369 & 2.08 \\
\hline pS88037 & sopA & $\begin{array}{l}\text { SopA protein (Plasmid partition } \\
\text { protein A) }\end{array}$ & 0.60 & 0.227 & 0.47 & 0.147 & 1.12 & 0.847 & 0.98 \\
\hline pS88038 & sop $B$ & $\begin{array}{l}\text { SopB protein (Plasmid partition } \\
\text { protein B) }\end{array}$ & 0.38 & 0.021 & 0.91 & 0.879 & 1.41 & 0.696 & 3.32 \\
\hline pS88039 & & Hypothetical protein & 0.63 & 0.312 & 2.19 & 0.330 & 3.82 & 0.031 & 2.96 \\
\hline pS88040 & & Conserved hypothetical protein & 0.73 & 0.510 & 2.74 & 0.240 & 3.61 & 0.031 & 3.61 \\
\hline pS88041 & & Hypothetical protein & 1.39 & 0.295 & 0.42 & 0.174 & 1.77 & 0.092 & 1.47 \\
\hline pS88043 & & Hypothetical protein & 0.89 & 0.782 & 1.47 & 0.378 & 2.00 & 0.188 & 1.83 \\
\hline pS88044 & yubl & Putative antirestriction protein & 1.35 & 0.720 & 1.13 & 0.890 & 0.99 & 0.991 & 3.38 \\
\hline pS88045 & & Conserved hypothetical protein & 0.95 & 0.919 & 1.66 & 0.403 & 1.09 & 0.873 & 4.52 \\
\hline pS88046 & & Conserved hypothetical protein & 0.80 & 0.717 & 1.38 & 0.661 & 1.25 & 0.735 & 2.07 \\
\hline pS88047 & $y d b A$ & Conserved hypothetical protein & 1.71 & 0.542 & 0.99 & 0.987 & 1.33 & 0.739 & 4.18 \\
\hline pS88048 & $y d c A$ & Putative adenine-specific DNA methylase & 1.44 & 0.652 & 1.09 & 0.917 & 1.52 & 0.606 & 3.98 \\
\hline pS88050 & ssb & Single-stranded DNA-binding protein & 1.56 & 0.383 & 2.42 & 0.152 & 1.96 & 0.211 & 2.91 \\
\hline pS88051 & yubl & Conserved hypothetical protein & 0.90 & 0.832 & 1.21 & 0.842 & 2.13 & 0.203 & 2.05 \\
\hline pS88054 & $y c j A$ & $\begin{array}{l}\text { Putative DNA-binding protein involved } \\
\text { in plasmid partitioning (ParB-like } \\
\text { partition protein) }\end{array}$ & 1.31 & 0.260 & 2.60 & 0.392 & 3.45 & 0.007 & 2.30 \\
\hline pS88055 & psiB & Plasmid SOS inhibition protein B & 0.74 & 0.414 & 5.34 & 0.094 & 3.26 & 0.026 & 4.03 \\
\hline pS88056 & psiA & Plasmid SOS inhibition protein A & 1.67 & 0.321 & 13.06 & 0.048 & 6.44 & 0.016 & 3.02 \\
\hline pS88057 & flmC & $\begin{array}{l}\text { Putative F-plasmid maintenance } \\
\text { protein C }\end{array}$ & 2.27 & 0.144 & 0.55 & 0.346 & 0.65 & 0.401 & 2.21 \\
\hline pS88059 & $y u b N$ & Conserved hypothetical protein & 2.01 & 0.441 & 0.90 & 0.902 & 1.20 & 0.826 & 3.52 \\
\hline pS88060 & yubO & Conserved hypothetical protein & 1.13 & 0.781 & 1.79 & 0.211 & 2.24 & 0.075 & 3.89 \\
\hline
\end{tabular}


Table 1 Transcriptional expression of pS88 and PAMM ORFs in different growth conditions compared to LB broth (Continued)

\begin{tabular}{|c|c|c|c|c|c|c|c|c|c|}
\hline pS88061 & yubP & Conserved hypothetical protein & 1.43 & 0.397 & 2.40 & 0.109 & 1.72 & 0.408 & 4.27 \\
\hline pS88062 & yubQ & $\begin{array}{l}\text { X polypeptide (P19 protein); Putative } \\
\text { transglycosylase }\end{array}$ & 0.94 & 0.948 & 0.88 & 0.910 & 1.20 & 0.852 & 4.90 \\
\hline pS88063 & tram & Protein TraM (Conjugal transfer protein M) & 0.77 & 0.313 & 0.94 & 0.866 & 0.92 & 0.769 & 0.25 \\
\hline pS88064 & traj & $\begin{array}{l}\text { Protein TraJ (Positive regulator of conjugal } \\
\text { transfer operon) }\end{array}$ & 0.39 & 0.212 & 2.86 & 0.310 & 1.08 & 0.898 & 1.98 \\
\hline pS88066 & $\operatorname{traA}$ & Fimbrial protein precursor TraA (Pilin) & 1.59 & 0.053 & 0.54 & 0.188 & 0.19 & 0.004 & 0.21 \\
\hline pS88092 & trat & $\begin{array}{l}\text { Complement resistance and surface } \\
\text { exclusion outer membrane protein TraT }\end{array}$ & 0.27 & 0.265 & 0.54 & 0.573 & 0.82 & 0.847 & 0.35 \\
\hline pS88095 & $\operatorname{trax}$ & F pilin acetylase TraX & 0.56 & 0.157 & 0.54 & 0.409 & 0.72 & 0.389 & 0.88 \\
\hline pS88096 & fino & $\begin{array}{l}\text { Fertility inhibition protein FinO } \\
\text { (Conjugal transfer repressor) }\end{array}$ & 0.49 & 0.127 & 0.98 & 0.968 & 0.88 & 0.732 & 1.21 \\
\hline pS88097 & yigA & Conserved hypothetical protein YigA & 1.22 & 0.803 & 2.08 & 0.427 & 0.95 & 0.953 & 0.50 \\
\hline pS88098 & yigB & Putative nuclease YigB & 0.46 & 0.241 & 0.47 & 0.463 & 1.34 & 0.648 & 2.34 \\
\hline pS88099 & repA2 & $\begin{array}{l}\text { Replication regulatory protein RepA2 } \\
\text { (Protein CopB) }\end{array}$ & 1.27 & 0.340 & 1.43 & 0.199 & 2.24 & 0.071 & 1.93 \\
\hline pS88100 & repA1 & Replication initiation protein RepA1 & 0.56 & 0.120 & 1.14 & 0.702 & 2.18 & 0.072 & 1.53 \\
\hline pS88101 & yacA & $\begin{array}{l}\text { Conserved hypothetical protein YacA. } \\
\text { possible repressor }\end{array}$ & 0.49 & 0.344 & 0.96 & 0.961 & 0.41 & 0.293 & 4.30 \\
\hline pS88102 & $y a c B$ & $\begin{array}{l}\text { Putative plasmid stabilization system } \\
\text { protein YacB }\end{array}$ & 0.31 & 0.169 & 0.64 & 0.502 & 0.32 & 0.227 & 1.57 \\
\hline pS88103 & yacc & Putative exoribonuclease YacC & 0.38 & 0.209 & 0.56 & 0.461 & 0.50 & 0.369 & 0.95 \\
\hline pS88104 & cia & Colicin-la & 5.11 & 0.105 & 21.06 & 0.023 & 6.03 & 0.087 & 70.36 \\
\hline pS88105 & $i m m$ & Colicin-la immunity protein & 1.10 & 0.944 & 5.58 & 0.048 & 3.46 & 0.106 & 3.17 \\
\hline pS88106 & $y b a A$ & Conserved hypothetical protein YbaA & 5.25 & 0.197 & 4.87 & 0.189 & 8.90 & 0.096 & 3.27 \\
\hline pS88108 & ydeA & Conserved hypothetical protein YdeA & 0.45 & 0.247 & 0.31 & 0.165 & 0.41 & 0.222 & 0.51 \\
\hline pS88109 & $y d f A$ & Conserved hypothetical protein YdfA & 0.17 & 0.119 & 0.69 & 0.733 & 0.36 & 0.284 & 0.58 \\
\hline pS88110 & & Putative acetyltransferase & 0.71 & 0.606 & 0.98 & 0.983 & 0.77 & 0.684 & 1.57 \\
\hline pS88111 & & Predicted dehydrogenase & 1.41 & 0.562 & 0.31 & 0.126 & 0.88 & 0.801 & 1.48 \\
\hline pS88112 & & Predicted dehydrogenase & 1.25 & 0.691 & 0.63 & 0.416 & 1.19 & 0.736 & 0.87 \\
\hline pS88113 & & Predicted dehydrogenase & 0.92 & 0.893 & 1.13 & 0.850 & 1.65 & 0.509 & 3.02 \\
\hline pS88114 & cvi & Microcin $\mathrm{V}$ immunity protein & 0.84 & 0.735 & 1.13 & 0.846 & 2.17 & 0.203 & 4.48 \\
\hline pS88115 & cvac & $\begin{array}{l}\text { Microcin } \vee \text { precursor (Microcin } V \\
\text { bacteriocin) }\end{array}$ & 21.96 & 0.007 & 17.27 & 0.010 & 29.58 & 0.016 & 61.11 \\
\hline pS88116 & $c v a B$ & $\begin{array}{l}\text { Microcin } \vee \text { secretion/processing } \\
\text { ATP-binding } \\
\text { protein CvaB }\end{array}$ & 12.88 & 0.010 & 17.55 & 0.001 & 19.43 & 0.006 & 162.02 \\
\hline pS88117 & craA & Microcin V secretion protein CvaA & 26.23 & 0.012 & 44.02 & 0.005 & 43.81 & 0.019 & 215.77 \\
\hline pS88118 & & Conserved hypothetical protein & 3.99 & 0.095 & 4.66 & 0.066 & 3.32 & 0.219 & 7.46 \\
\hline pS88123 & & $\begin{array}{l}\text { Putative Phospho-2-dehydro-3- } \\
\text { deoxyheptonatealdolase }\end{array}$ & 354.6 & 0.000 & 190.9 & 0.001 & 109.6 & 0.006 & 144.67 \\
\hline pS88124 & iroN & IroN. Salmochelin siderophore receptor & 2.94 & 0.137 & 2.14 & 0.465 & 1.95 & 0.394 & 28.97 \\
\hline pS88128 & $\operatorname{iroB}$ & IroB. Putative glucosyltransferase & 72.17 & 0.001 & 48.95 & 0.002 & 37.97 & 0.014 & 69.71 \\
\hline pS88130 & & Conserved hypothetical protein & 1.84 & 0.336 & 3.36 & 0.198 & 10.36 & 0.029 & 3.10 \\
\hline pS88131 & & Conserved hypothetical protein & 2.43 & 0.318 & 9.11 & 0.031 & 13.83 & 0.039 & 14.66 \\
\hline pS88132 & & Hypothetical protein & 0.20 & 0.013 & 0.95 & 0.871 & 0.63 & 0.482 & 0.40 \\
\hline pS88133 & iss & Iss (Increased serum survival) & 0.28 & 0.083 & 0.48 & 0.282 & 0.36 & 0.151 & 0.66 \\
\hline pS88136 & & Hypothetical protein & 0.93 & 0.896 & 1.51 & 0.618 & 1.71 & 0.391 & 0.65 \\
\hline
\end{tabular}




\begin{tabular}{|c|c|c|c|c|c|c|c|c|}
\hline pS88137 & $\begin{array}{l}\text { Conserved hypothetical protein; } \\
\text { Putative GTPase }\end{array}$ & 0.40 & 0.263 & 0.52 & 0.504 & 0.64 & 0.580 & 1.59 \\
\hline pS88142 & Conserved hypothetical protein & 0.51 & 0.096 & 0.48 & 0.134 & 0.77 & 0.458 & l \\
\hline pS88143 & Conserved hypothetical protein & 0.57 & 0.090 & 0.70 & 0.646 & 0.84 & 0.750 & l \\
\hline pS88146 etsC & $\begin{array}{l}\text { Putative type I secretion outer } \\
\text { membrane } \\
\text { protein EtsC }\end{array}$ & 1.05 & 0.893 & 0.42 & 0.208 & 0.78 & 0.478 & 0.61 \\
\hline pS88148 etsA & $\begin{array}{l}\text { Putative type I secretion membrane- } \\
\text { fusion } \\
\text { protein EtsA }\end{array}$ & 0.49 & 0.126 & 0.34 & 0.211 & 0.36 & 0.050 & 0.31 \\
\hline pS88154 & Hypothetical protein & 0.47 & 0.330 & 4.44 & 0.163 & 1.25 & 0.790 & 3.00 \\
\hline pS88155 ompT & Outer membrane protease (omptin) & 0.48 & 0.178 & 0.43 & 0.092 & 0.42 & 0.137 & 0.37 \\
\hline pS88156 hlyF & Hemolysin HlyF & 1.02 & 0.981 & 0.44 & 0.402 & 0.72 & 0.507 & 0.14 \\
\hline pS88157 & $\begin{array}{l}\text { Conserved hypothetical protein; } \\
\text { putative Mig-14 protein }\end{array}$ & 1.11 & 0.921 & 0.47 & 0.376 & 0.94 & 0.942 & 0.11 \\
\hline S88-1832 gapA ${ }^{d}$ & $\begin{array}{l}\text { Glyceraldehyde-3-phosphate } \\
\text { dehydrogenase }\end{array}$ & 1.70 & 0.396 & 0.46 & 0.254 & 1.15 & 0.789 & 0.90 \\
\hline S88-0266 $\operatorname{din} B^{d}$ & DNA polymerase IV & 0.69 & 0.343 & 2.36 & 0.131 & 0.69 & 0.317 & 0.90 \\
\hline S88-4457 yjaD ${ }^{d}$ & NADH pyrophophatase & 0.85 & 0.586 & 0.91 & 0.698 & 1.26 & 0.344 & 1.24 \\
\hline
\end{tabular}

${ }^{a}$ Fold changes of transcription levels relative to reference condition (growth in LB). Fold change $>4$ are in bold print.

${ }^{b} \mathrm{p}$ value in Student's $\mathrm{t}$ test for the comparison of the three biological replicates for each experiment in different growth conditions and the reference condition. $\mathrm{p}<0.05$ are in bold print.

${ }^{c}$ ORFs present in plasmid pS88 but absent from plasmid pAMM. ${ }^{d}$ Housekeeping genes.

\section{Expression of iron uptake systems}

The concentration of free iron in human urine and serum is low, because iron is sequestered by host molecules [22-24]. E. coli has developed several strategies to acquire iron in such environments. Ten ORFs were upregulated after growth in urine, in serum, and in irondepleted LB, suggesting they were induced by the low iron concentrations in these media. Five of these 10 ORFs corresponded to iron-uptake and iron-assimilation systems, namely iutA and $i u c A$ (aerobactin), iroB (salmochelin) and sitA and sitB (SitABCD iron transport system). These iron-uptake systems have previously been linked to the virulence of ExPEC and APEC [4,7-9,24-27]. Mobley et al. also observed upregulation of UPEC ironacquisition systems such as aerobactin, salmochelin and the SitABCD system in urinary isolates from experimentally infected mice and from women with UTI $[14,16]$. Likewise, Li et al. found that genes involved in iron acquisition were among the most significantly upregulated genes during growth in chicken serum of the APEC strain O1 [28], which harbours a plasmid (pAPEC-O1-ColBM) closely related to pS88 [3]. Our study represents the first transcriptional analysis of an E. coli plasmid after growth in human serum.

Surprisingly, we found that the salmochelin receptor iroN was not upregulated in our ex vivo experiments, and that the transcript level of the aerobactin receptor iutA was markedly lower than that of the siderophore
iucA. In contrast the salmochelin receptor iroN was upregulated 28-fold in the isolate from a neonate with UTI. Such discrepancies have been previously described. In the murine UTI model used by Mobley et al. [16], iroN was upregulated but its transcript level was also lower than that of iroB. Moreover, in their transcriptome analysis of $E$. coli isolates from eight women with urinary tract infection, iroN and iutA were only upregulated in two isolates [14].

\section{Colicin expression}

Another group of genes upregulated in iron-deficient conditions were the genes encoding the Microcin $\mathrm{V}$ $(c v a A, c v a B, c v a C)$ and Colicin Ia, which were also upregulated in human serum and urine. Previous reports have shown the influence of bacterial intracellular iron levels on colicin expression, but the reason of such induction is still poorly understood [29-31]. Of note, transcription of immunity protein for both colicins was not upregulated in any of the conditions studied except for Colicin Ia in human serum.

\section{Expression of ORFs of unknown function in iron-deficient environments}

Two ORFs with unknown functions, shiF and ORF 123, were upregulated in iron-deficient conditions, with large fold changes in vivo and ex vivo. 
ORF 123 was the most strongly upregulated (> 100fold) in the 3 test conditions, and was expressed 3 to 4 times more strongly than the iron acquisition systems. A nucleotide homology search using the BLAST program [32] showed that ORF 123 is highly homologous (99\%) to an ORF present in E. coli plasmids possessing a CVP region (such pAPEC-O1-ColI-BM, pAPEC-O2-ColV and pAPEC-1) or located on the chromosome of UPEC strains such as CFT073 (ORF c1220; 94\%) and 536 (ORF ECP-0281; 95\%). No homologous gene is found in the commensal E. coli strain MG1655. Transcriptome analysis by Mobley et al. [16] showed overexpression of c1220 transcripts in E. coli CFT073 in a mouse model of UTI. The putative protein encoded by ORF 123 showed $45-50 \%$ identity to three phospho-2dehydro-3-deoxyheptonate aldolases that catalyze the first reaction of the shikimate pathway and are present on the chromosome of E. coli K12. This pathway involves seven enzymatic reactions that generate chorismate, a factor involved in the synthesis of three aromatic amino acids (tyrosine, tryptophan and phenylalanine) [33]. However, this pathway is also involved in other reactions, such as biosynthesis of siderophore group nonribosomal peptides such as yersiniabactin and enterobactin. In plasmid pS88, as in other CVP-containing plasmids, ORF 123 lies just upstream of iroN and is preceded by a sequence resembling the Fur Box consensus sequence (5'-GATAATGATAATCATTATC) [34,35]. BLAST analysis of complete genomes available on publicly available database showed that ORF 123 is only found when the salmochelin operon is present but the reciprocity is not true, as for example in strain UTI89, which harbors only an iro locus. On the chromosome of E. coli strains CFT073 and 536, this ORF (c1220 and ECP_0281, respectively) is located in a pathogenicity island containing an iro locus but is $20-30 \mathrm{~kb}$ distant from the iro locus. Because of its putative function, its high inducibility in iron-depleted conditions, and its physical proximity to the iro locus, we suspected that this ORF might be an auxiliary gene that boosts the synthesis of iron acquisition systems such as salmochelin by enhancing the production of chorismate and, consequently, enterobactin, the precursor of salmochelin [36].

The shiF ORF was also upregulated in iron-deficient environments. ShiF was first described in the pathogenicity island SHI-2 in Shigella flexneri [37] and encodes a putative protein belonging to the major facilitator superfamily. The latter is one of the two largest families of membrane transporters capable of transporting small solutes in response to chemiosmotic ion gradients. Transcriptome analysis of APEC O1 grown in chicken serum showed that shiF was also upregulated [28]. BLAST analysis revealed that $s h i F$ is present in many UPEC and APEC strains, but only when the locus encoding aerobactin is present, although the two do not always colocalize. Of interest, in pS88, as in Shi-2, shiF is located just upstream of the aerobactin operon, on the opposite strand, and shares the same Fur Box. These results suggest that shiF induction is at least partly regulated by iron deficiency and that, like ORF 123, shiF may be an auxiliary gene that promotes the transport of lysine, the precursor of aerobactin.

\section{Specific ORF expression in serum and urine}

A minority of ORFs were upregulated in serum and/or urine but not in iron-depleted LB broth. Two of these ORFs were upregulated only in urine (ORFs 17 and 130), while 2 ORFs were upregulated in both serum and urine (psiA and ORF 131). Meanwhile the putative role of ORF 130, ORF 131 and psiA in the steps studied could not be predicted, the most strongly upregulated ORF in urine, ORF 17, could play a role in the infection process. This ORF codes for a putative enolase, an enzyme involved in the penultimate step of glycolysis and that catalyses 2-phosphoglycerate conversion to phosphoenolpyruvate. Intriguingly this latter molecule is the substrate of the phospho-2-dehydro-3-deoxyheptonate aldolase involved in the shikimate pathway. ORF 17 might therefore help to optimize the synthesis of ironuptake systems in urine.

\section{Other putative virulence genes}

Other putative virulence factors like ompTp, ets $C$, iss and $h l y F[10-13,38,39]$ were not upregulated in any of the conditions studied here. Nolan et al. has reported upregulation of the ets $A B C$ genes (but not iss) in APEC O1 strains, including pAPEC-O1-ColBM, grown in chicken serum at $37^{\circ} \mathrm{C}$ [28]. In contrast, in their transcriptional analysis of 8 genes in pAPEC-O2-ColV grown in chicken serum and human urine, they found that iss, but not ets $C$, was upregulated in chicken serum [40]. Moreover, $h l y F$ was also upregulated in chicken serum but not in human urine. Variability between commercial chicken serum could explain the observed differences in the previously mentioned studies. Alternatively, these putative virulence genes may be induced in highly specific conditions that remain to be determined.

\section{Conclusion}

While several studies have examined E. coli virulence gene expression in animal models, little is known about their expression during human infection [14,15]. Here we identified several genes that may play a key role during E. coli growth in human serum and urine. Further studies are necessary to determine the roles of these candidate virulence genes and to understand the contribution of plasmid pS88 to the virulence of E. coli strain 
S88, in particular its aptitude to cross the human bloodbrain barrier.

\section{Methods \\ Bacteria}

E. coli meningitis strain S88, representative of the French clonal group $\mathrm{O} 45: \mathrm{K} 1: \mathrm{H} 7$, has been shown to harbor a virulence plasmid of $134 \mathrm{~kb}$, designated pS88 [3]. E. coli strains responsible for UTI in young infants were screened for transcriptional analysis in vivo, as follows. The O45-specific genes and $\mathrm{K} 1$ capsular antigen were detected as described elsewhere $[41,42]$. The presence of iss, etscC, $h l y F, o m p T_{p}$ and $c v a A$, together with the genes encoding salmochelin (iroN), aerobactin (iucC) and the iron-uptake system SitABCD (sitA), considered to be a signature of a conserved virulence plasmidic (CVP) region characteristic of pS88 [38], were sought by PCR as previously described [3].

\section{Growth conditions}

An overnight culture of strain S88 in Luria Bertani (LB) broth (Sigma) was diluted 1/100 in LB broth and grown at $37^{\circ} \mathrm{C}$ with agitation until optical density at $600 \mathrm{~nm}$ $\left(\mathrm{OD}_{600}\right)$ reached 0.65 . This culture represented the reference condition for this study. Strain S88 was also grown in LB broth containing the iron chelator 2,2'-dipyridyl (Sigma, Saint Quentin Fallavier, France) at a final concentration of $200 \mu \mathrm{M}$, as previously described [43]. With their informed consent, serum was collected at Etablissement Français du Sang from healthy blood donors aged from 20 to 40 years who had no history of infection or antibiotic use in the previous 2 months. Serums from 20 donors were pooled and aliquots of $500 \mu \mathrm{l}$ were stored at $-80^{\circ} \mathrm{C}$ until use. Transcriptome analysis of E. coli cultured in serum was performed as follows: an overnight culture of S88 in LB broth was diluted 1/10 in physiological saline, then $250 \mu \mathrm{l}$ of this dilution was mixed with $250 \mu \mathrm{l}$ of serum and incubated at $37^{\circ} \mathrm{C}$ for 3 hours; the culture was centrifuged for $7 \mathrm{~min}$ at $9000 \mathrm{~g}$ and $21^{\circ} \mathrm{C}$ in a microcentrifuge (Jouan) and the pellet was resuspended in $500 \mu \mathrm{l}$ of physiological saline. RNA was immediately stabilized with RNA Protect Bacterial Reagent (QIAGEN) and the sample was stored at $-20^{\circ} \mathrm{C}$ until RNA extraction. With their parents' informed consent, sterile urine was collected from healthy children aged from 3 months to 5 years who had no history of UTI or antibiotic use in the previous 2 months, and was stored in aliquots of $5 \mathrm{ml}$ at $-20^{\circ} \mathrm{C}$. An overnight culture of S88 in LB broth was diluted $1 / 100$ in the pooled urine and cultured at $37^{\circ} \mathrm{C}$ until $\mathrm{OD}_{600}$ reached 0.25 (preliminary experiments showed that this represented the midexponential phase of growth in urine). RNA was then stabilized as described above. To analyze the regulation of pS88 expression in vivo, aliquots of fresh urine were obtained from children aged no more than 3 months who had been admitted to Robert-Debré Hospital for fever and whose urine contained $\geq 10^{6}$ leukocytes per $\mathrm{ml}$ and numerous Gram-negative rods. The samples were immediately treated with RNA Protect Bacterial Reagent (QIAGEN) and stored at $-20^{\circ} \mathrm{C}$ until RNA extraction. If urine culture yielded $\geq 10^{5}$ E. coli $\mathrm{CFU} / \mathrm{ml}$ and no other bacteria, confirming the diagnosis of UTI, the serotype was determined and genes characteristic of the CVP region were sought as described above. Among the 10 isolates analyzed, one, designated AMM, was recovered in 2010 from urine of a 2-month-old infant with acute pyelonephritis and no medical history. This strain, belonged to ST95, was of serogroup O45:K1 and harbored the main chromosomal virulence genes (fuy $A$, papC, papGII) and the CVP region, indicating that AMM belongs to the O45:K1 clonal group and is very similar to S88. PCRs specific for 88 plasmidic ORFs of interest (see below) showed that the pAMM plasmid possessed 82 of these ORFs. RNA was extracted as described above, directly from urine stored at $-20^{\circ} \mathrm{C}$, and after growth in LB (reference condition).

\section{RNA extraction}

RNA from ex vivo and in vivo samples was extracted with the RNeasy Mini kit (QIAGEN) according to the manufacturer's instructions. Total RNA was then isolated with the RNase-Free DNase set (QIAGEN). The concentration of total RNA was determined with ND1000 spectrophotometer (NanoDrop) and adjusted to a final concentration of $0.05 \mu \mathrm{g} / \mu \mathrm{l}$.

\section{Quantitative reverse transcription-PCR (qRT-PCR)}

For transcriptome analysis, all ORFs of unknown function and between 1 and 4 ORFs with known functions at each plasmid locus except most genes corresponding to plasmid transfer systems, insertion sequences and transposases were chosen. A total of 88 plasmid transcripts were retained for investigation. As previously recommended [44], three housekeeping genes were used for normalization, chosen among previously described genes $(\operatorname{gap} A, \operatorname{din} B$ and $y j a D)[16,45]$. Primers were designed with Primer 3 software [46]. Assays were performed in microplates (Eurogentec), the primer pairs being distributed directly at a concentration of $200 \mathrm{nM}$ with a Eurogentec device. Reverse transcriptase (EuroScript RT, $0.125 \mathrm{U} / \mu \mathrm{l})$ and RNA extract $(0.05 \mu \mathrm{g} / \mu \mathrm{l})$ were added to the One-step MESA GREEN qRT-PCR MasterMix Plus for SYBR assay (Eurogentec) according to the manufacturer's instructions, and the mix was distributed in the microplates ( $0.05 \mu \mathrm{g}$ of RNA in each final reaction mix). Reverse transcription and amplification were performed with an LC480 Light Cycler (Roche) in one step with the following cycling parameters: $30 \mathrm{~min}$ at $48^{\circ} \mathrm{C}$ for reverse 
transcription, $5 \mathrm{~min}$ at $95^{\circ} \mathrm{C}$ for reverse transcriptase inactivation and Taq activation, and 45 cycles of $15 \mathrm{~s}$ at $95^{\circ} \mathrm{C}, 20 \mathrm{~s}$ at $60^{\circ} \mathrm{C}$ and $40 \mathrm{~s}$ at $72^{\circ} \mathrm{C}$. Melting curve analysis of each reaction product was used to control the specificity of qRT-PCR.

\section{Data and statistical analysis}

The cycle threshold $(\mathrm{Ct})$ was automatically determined by using the Second Derivative Maximum Method included in LC480 software. The Ct values provided by the qRT-PCR instrument were imported into a spreadsheet program (Microsoft Excel). The fold change in the abundance of the 88 ORF transcripts between each test condition (growth in LB with 2,2'-dipyridyl, serum and urine) and the reference condition (growth in LB) was calculated by using the $2^{-\Delta \Delta C T}$ method $[47,48]$. The average of 3 housekeeping genes $(\operatorname{gap} A, \operatorname{din} B, y j a D)$ was used for the normalization [44]. Briefly, the first $\Delta \mathrm{Ct}$ represents the difference of $\mathrm{Ct}$ between the investigated gene and the average of the 3 housekeeping genes and the $\Delta \Delta \mathrm{Ct}$ is then calculated using the formula $\Delta \Delta \mathrm{Ct}=\Delta \mathrm{Ct}$ (test condition)- $\Delta \mathrm{Ct}$ (reference condition). For transcriptome analysis during growth in vitro and ex vivo, three independent experiments (biological and technical replicates) were performed in each condition, including growth, RNA extraction and qRT-PCR. The in vivo experiment was performed only once because of the limited available amount of urine.

A $p$ value for each ORF was calculated by using Student's $t$ test to compare the three replicates for each bacterial growth condition.

\section{Competing interest}

All authors declare no financial competing interests.

\section{Authors contributions}

$\mathrm{CL}$ carried out all transcriptomic studies and participated in study design. SB and PB conceived of the study, and participated in its design and coordination and wrote the manuscript. EB participated in study design and helped to draft the manuscript. All authors read and approved the final manuscript.

\section{Acknowledgments}

This work was supported in part by the "Fondation pour la Recherche Médicale" for CL. This funding had no role in design, analysis, and interpretation of data; or in writing of the manuscript.

Received: 9 February 2012 Accepted: 7 June 2012 Published: 21 June 2012

\section{References}

1. Bidet P, Mahjoub-Messai F, Blanco J, Blanco J, Dehem M, Aujard Y, Bingen E, Bonacorsi S: Combined Multilocus Sequence Typing and O Serogrouping Distinguishes Escherichia coli Subtypes Associated with Infant Urosepsis and/or Meningitis. J Infect Dis 2007, 196:297-303.

2. Bonacorsi S, Clermont O, Houdouin V, Cordevant C, Brahimi N, Marecat A, Tinsley C, Nassif $X$, Lange M, Bingen E: Molecular analysis and experimental virulence of french and north american Escherichia coli neonatal meningitis isolates; Identification of new virulent clone. $J$ Infect Dis 2003, 187:1895-1906.
3. Peigne $C$, Bidet $P$, Mahjoub-Messai F, Plainvert $C$, Barbe $V$, Medigue $C$, Frapy E, Nassif X, Denamur E, Bingen E, et al: The plasmid of Escherichia coli strain $\mathrm{S} 88$ (O45:K1:H7) that causes neonatal meningitis is closely related to avian pathogenic E. coli plasmids and is associated with high-level bacteremia in a neonatal rat meningitis model. Infect Immun 2009, 77(6):2272-2284.

4. Johnson TJ, Siek KE, Johnson SJ, Nolan LK: DNA sequence of a ColV plasmid and prevalence of selected plasmid-encoded virulence genes among avian Escherichia coli strains. J Bacteriol 2006, 188(2):745-758.

5. Mahjoub-Messai F, Bidet P, Caro V, Diancourt L, Biran V, Aujard Y, Bingen E, Bonacorsi S: Escherichia coli isolates causing bacteremia via gut translocation and urinary tract infection in young infants exhibit different virulence genotypes. J Infect Dis 2011, 203(12):1844-1849.

6. Mellata MAK, Mo H, Curtiss R 3rd: Characterization of the contribution to virulence of three large plasmids of avian pathogenic Escherichia coli chi7122 (O78:K80:H9). Infect Immun 2010, 78(4):1528-1541.

7. Caza M, Lepine F, Milot S, Dozois CM: Specific roles of the iroBCDEN genes in virulence of an avian pathogenic Escherichia coli 078 strain and in production of salmochelins. Infect Immun 2008, 76(8):3539-3549. Epub 2008 Jun 3539.

8. Johnson JR, Moseley SL, Roberts PL, Stamm WE: Aerobactin and other virulence factor genes among strains of Escherichia coli causing urosepsis: association with patient characteristics. Infect Immun 1988, 56(2):405-412.

9. Sabri M, Leveille S, Dozois CM: A SitABCD homologue from an avian pathogenic Escherichia coli strain mediates transport of iron and manganese and resistance to hydrogen peroxide. Microbiology 2006, 152(Pt 3):745-758.

10. Chuba PJ, Leon MA, Banerjee A, Palchaudhuri S: Cloning and DNA sequence of plasmid determinant iss, coding for increased serum survival and surface exclusion, which has homology with lambda DNA. Mol Gen Genet 1989, 216(2-3):287-292.

11. Nolan LK, Giddings CW, Horne SM, Doetkott C, Gibbs PS, Wooley RE, Foley SL: Complement resistance, as determined by viable count and flow cytometric methods, and its association with the presence of iss and the virulence of avian Escherichia coli. Avian Dis 2002, 46(2):386-392.

12. Stumpe S, Schmid R, Stephens DL, Georgiou G, Bakker EP: Identification of OmpT as the protease that hydrolyzes the antimicrobial peptide protamine before it enters growing cells of Escherichia coli. J Bacteriol 1998, 180(15):4002-4006

13. Morales C, Lee MD, Hofacre C, Maurer JJ: Detection of a novel virulence gene and a Salmonella virulence homologue among Escherichia coli isolated from broiler chickens. Foodborne Pathog Dis 2004, 1(3):160-165.

14. Hagan EC, Lloyd AL, Rasko DA, Faerber GJ, Mobley HL: Escherichia coli global gene expression in urine from women with urinary tract infection. PLOS 2010, 6(11):e1001187.

15. Roos V, Klemm P: Global gene expression profiling of the asymptomatic bacteriuria Escherichia coli strain 83972 in the human urinary tract. Infect Immun 2006, 74(6):3565-3575.

16. Snyder JA, Haugen BJ, Buckles EL, Lockatell CV, Johnson DE, Donnenberg MS, Welch RA, Mobley HL: Transcriptome of uropathogenic Escherichia coli during urinary tract infection. Infect Immun 2004, 72(11):6373-6381.

17. Zdziarski J, Brzuszkiewicz E, Wullt B, Liesegang H, Biran D, Voigt B, Gronberg-Hernandez J, Ragnarsdottir B, Hecker M, Ron EZ, et al: Host imprints on bacterial genomes-rapid, divergent evolution in individual patients. PLOS Pathog 2010, 6(8):e1001078.

18. Houdouin V, Bonacorsi S, Bidet P, de La Rocque F, Cohen R, Aujard Y, Bingen E: Clinical outcome and bacterial characteristics of 99 Escherichia coli meningitis in young infants. Arch Pediatr 2008, 15(Suppl 3):S138-S147.

19. Bortolussi R, Ferrieri P, Wannamaker LW: Dynamics of Escherichia coli infection and meningitis in infant rats. Infect Immun 1978, 22(2):480-485.

20. Dietzman DE, Fischer GW, Schoenknecht FD: Neonatal Escherichia coli septicemia-bacterial counts in blood. J Pediatr 1974, 85(1):128-130.

21. Glode MP, Sutton A, Moxon ER, Robbins JB: Pathogenesis of neonatal Escherichia coli meningitis: induction of bacteremia and meningitis in infant rats fed Escherichia coli K1. Infect Immun 1977, 16(1):75-80.

22. Che $P, X u J$, Shi $H, M a ~ Y$ : Quantitative determination of serum iron in human blood by high-performance capillary electrophoresis. J Chromatogr B Biomed Appl 1995, 669(1):45-51.

23. Johnson JR, Goullet P, Picard B, Moseley SL, Roberts PL, Stamm WE: Association of carboxylesterase B electrophoretic pattern with presence 
and expression of urovirulence factor determinants and antimicrobial resistance among strains of Escherichia coli that cause urosepsis. Infect Immun 1991, 59(7):2311-2315.

24. Russo TA, Carlino UB, Mong A, Jodush ST: Identification of genes in an extraintestinal isolate of Escherichia coliwith increased expression after exposure to human urine. Infect Immun 1999, 67(10):5306-5314.

25. Johnson JR, O'Bryan TT, Kuskowski M, Maslow JN: Ongoing horizontal and vertical transmission of virulence genes and papA alleles among Escherichia coli blood isolates from patients with diverse-source bacteremia. Infect Immun 2001, 69(9):5363-5374.

26. Runyen-Janecky $\sqcup$, Reeves SA, Gonzales EG, Payne SM: Contribution of the Shigella flexneri Sit, luc, and Feo iron acquisition systems to iron acquisition in vitro and in cultured cells. Infect Immun 2003, 71(4):1919-1928.

27. Zhou D, Hardt WD, Galan JE: Salmonella typhimurium encodes a putative iron transport system within the centisome 63 pathogenicity island. Infect Immun 1999, 67(4):1974-1981.

28. Li G, Tivendale KA, Liu P, Feng Y, Wannemuehler Y, Cai W, Mangiamele $P$, Johnson TJ, Constantinidou C, Penn CW, et al: Transcriptome analysis of avian pathogenic Escherichia coli $\mathrm{O} 1$ in chicken serum reveals adaptive responses to systemic infection. Infect Immun 2011, 79(5):1951-1960.

29. Boyer AE, Tai PC: Characterization of the $c v a A$ and cvi promoters of the colicin V export system: iron-dependent transcription of $\mathrm{cvaA}$ is modulated by downstream sequences. J Bacteriol 1998, 180(7):1662-1672.

30. Chehade $\mathrm{H}$, Braun V: Iron-regulated synthesis and uptake of colicin V. FEMS Microbio/ 1988, Lett. 52:177-182

31. Gilson L, Mahanty HK, Kolter R: Genetic analysis of an MDR-like export system: the secretion of colicin V. EMBO J 1990, 9(12):3875-3884.

32. Altschul SF, Madden TL, Schaffer AA, Zhang J, Zhang Z, Miller W, Lipman DJ: Gapped BLAST and PSI-BLAST: a new generation of protein database search programs. Nucleic Acids Res 1997, 25(17):3389-3402.

33. Herrmann KM, Weaver LM: The shikimate pathway. Annu Rev Plant Physio Plant Mol Biol 1999, 50:473-503.

34. Bagg A, Neilands JB: Molecular mechanism of regulation of siderophoremediated iron assimilation. Microbiol Rev 1987, 51(4):509-518.

35. de Lorenzo V, Wee S, Herrero M, Neilands JB: Operator sequences of the aerobactin operon of plasmid ColV-K30 binding the ferric uptake regulation (fur) repressor. J Bacteriol 1987, 169(6):2624-2630.

36. Bister BBD, Nicholson GJ, Valdebenito M, Schneider K, Winkelmann G, Hantke K, Süssmuth RD: The structure of salmochelins: C-glucosylated enterobactins of Salmonella enterica. Biometals 2004, 17(4):471-481.

37. Moss JE, Cardozo TJ, Zychlinsky A, Groisman EA: The selC-associated SHI-2 pathogenicity island of Shigella flexneri. Mol Microbiol 1999, 33(1):74-83.

38. Johnson TJ, Johnson SJ, Nolan LK: Complete DNA sequence of a ColBM plasmid from avian pathogenic Escherichia coli suggests that it evolved from closely related ColV virulence plasmids. J Bacteriol 2006, 188(16):5975-5983.

39. Rodriguez-Siek KE, Giddings CW, Doetkott C, Johnson TJ, Fakhr MK, Nolan LK: Comparison of Escherichia coli isolates implicated in human urinary tract infection and avian colibacillosis. Microbiology 2005, 151(Pt 6):2097-2110

40. Skyberg JA, Johnson TJ, Nolan LK: Mutational and transcriptional analyses of an avian pathogenic Escherichia coli ColV plasmid. BMC Microbiol 2008, 8:24.

41. Bidet $P$, Metais A, Mahjoub-Messai F, Durand L, Dehem M, Aujard Y, Bingen E, Nassif X, Bonacorsi S: Detection and identification by PCR of a highly virulent phylogenetic subgroup among extraintestinal pathogenic Escherichia coli B2 Strains. Appl Environ Microbiol 2007, 73(7):2373-2377.

42. Plainvert $C$, Bidet $P$, Peigne $C$, Barbe $V$, Medigue $C$, Denamur E, Bingen E, Bonacorsi S: A new O-antigen gene cluster has a key role in the virulence of the Escherichia coli meningitis clone 045:K1:H7. J Bacteriol 2007, 189(23):8528-8536.

43. Negre $V L$, Bonacorsi $S$, Schubert $S$, Bidet $P$, Nassif $X$, Bingen E: The siderophore receptor IroN, but not the high-pathogenicity island or the hemin receptor ChuA, contributes to the bacteremic step of Escherichia coli neonatal meningitis. Infect Immun 2004, 72(2):1216-1220.

44. Vandesompele J, De Preter K, Pattyn F, Poppe B, Van Roy N, De Paepe A Speleman F: Accurate normalization of real-time quantitative RT-PCR data by geometric averaging of multiple internal control genes. Genome Biol 2002, 3(7):Research0034.
45. Le Gall T, Darlu P, Escobar-Paramo P, Picard B, Denamur E: Selection-driven transcriptome polymorphism in Escherichia coli/Shigella species. Genome Res 2005, 15(2):260-268.

46. Rozen S, Skaletsky H: Primer3 on the WWW for general users and for biologist programmers. In Bioinformatics Methods and Protocols: Methods in Molecular Biology. Edited by Krawetz S, Misener S. Totowa, NJ: Humana Press; 2000:365-386.

47. Schmittgen TD, Livak KJ: Analyzing real-time PCR data by the comparative C(T) method. Nat Protoc 2008, 3(6):1101-1108

48. Thellin O, Zorzi W, Lakaye B, De Borman B, Coumans B, Hennen G, Grisar T, Igout $A$, Heinen $E$ : Housekeeping genes as internal standards: use and limits. J Biotechnol 1999, 75(2-3):291-295.

doi:10.1186/1471-2180-12-115

Cite this article as: Lemaitre et al:: Transcriptional analysis of the Escherichia coli ColV-la plasmid pS88 during growth in human serum and urine. BMC Microbiology 2012 12:115

\section{Submit your next manuscript to BioMed Central and take full advantage of:}

- Convenient online submission

- Thorough peer review

- No space constraints or color figure charges

- Immediate publication on acceptance

- Inclusion in PubMed, CAS, Scopus and Google Scholar

- Research which is freely available for redistribution 